\title{
Pengembangan Lembar Kerja Siswa Kimia Berbasis Problem Based Learning Untuk Meningkatkan Partisipasi dan Hasil Belajar Siswa SMA Kelas X
}

\author{
Yeni Trianah \\ Universtas Musi Rawas \\ trianah.yeni@yahoo.com
}

Abstrak: Penelitian ini bertujuan untuk (1) menghasilkan produk LKS kimia berbasis PBL yang layak digunakan untuk meningkatkan partisipasi dan hasil belajar siswa, (2) mengkaji peningkatan partisipasi dan hasil belajar siswa kelas $\mathrm{X}$ dengan menggunakan LKS berbasis PBL, dan (3) mengkaji respon siswa kelas X setelah menggunakan LKS berbasis PBL. Penelitian ini merupakan penelitian pengembangan atau Research and Development (R \& D) dengan menggunakan model 4D, yaitu Define, Design, Develop, dan Disseminate. Hasil dari penelitian ini adalah (1) dihasilkan LKS Kimia berbasis PBL yang layak untuk untuk meningkatkan partisipasi dan hasil belajar siswa SMA kelas X dengan penilaian sangat baik serta reliabilitas berdasarkan nilai koefisien alpha secara berturutturut pada LKS I, II yaitu 0,935 (istimewa), 0,972 (istimewa) dan nilai korelasi antar rater secara berturut-turut pada LKS I, II yaitu 0,877 (istimewa), 0,946 (istimewa), (2) peningkatan partisipasi dan hasil belajar siswa ditunjukkan oleh nilai standard gain berturut-turut sebesar 0,09 (rendah) dan 0,5 (sedang), (3) respon siswa setelah menggunakan LKS kimia berbasis PBL bernilai 4,17 dan 4,23 keduanya berkategori baik.

Kata Kunci: LKS, Problem Based Learning, partisipasi, hasil belajar.

\section{PENDAHULUAN}

Pelajaran kimia salah satu pelajaran yang dianggap sulit oleh sebagian siswa. Anggapan sulit tersebut dibuktikan dengan pendapat siswa bahwa pelajaran kimia itu terlalu banyak rumus, membosankan, dan tidak menguasai pelajaran kimia. Ketidaktahuan siswa mengenai kegunaan kimia dalam kehidupan sehari-hari menjadi penyebab mereka cepat bosan dan tidak tertarik pada pelajaran kimia. Pelaksanaan pembelajaran kimia melibatkan proses sains dalam memperoleh suatu konsep. Inti dari pembelajaran kimia itu sendiri meliputi proses-proses sains yang dalam pembelajarannya memerlukan interaksi dengan obyek nyata serta interaksi dengan lingkungan belajarnya (Trianah, 2020). Sehingga peserta didik tidak hanya mendapatkan pengetahuan saja tetapi juga keterampilan proses dalam memecahkan masalah. Pada kenyataannya, proses pembelajaran kimia selama ini masih didominasi oleh guru, yakni siswa mendapatkan pemahaman mengenai konsep kimia masih dari penjelasan guru.

Dalam proses pembelajaran di sekolah, agar siswa ikut terlibat aktif serta dapat memperoleh pengetahuannya secara mandiri, maka dibutuhkan bantuan sumber-sumber belajar yang dapat meminimalkan peran guru namun lebih mengaktifkan siswa. Lembar Kerja Siswa (LKS) merupakan suatu bahan ajar cetak berupa lembar-lembar kertas yang berisi materi, ringkasan, dan petunjuk-petunjuk pelaksanaan tugas pembelajaran yang harus dikerjakan oleh peserta didik, yang mengacu pada kompetensi dasar yang harus dicapai, sehingga dalam pembelajarannya, siswa mendapatkan pengetahuan dengan melakukan kegiatan sesuai petunjuk LKS, bukan dari penjelasan guru (Sulistiyono, 2017).

LKS dapat digunakan untuk membantu siswa dalam melaksanakan kegiatan pembelajaran yang di dalamnya melibatkan proses-proses sains untuk memperoleh suatu konsep kimia (Lisnawati, 2021). Oleh karena itu dibutuhkan suatu model pembelajaran yang mendukung siswa dalam melaksanakan kegiatan pembelajaran tersebut. Model PBL merupakan suatu model pembelajaran yang melibatkan siswa untuk memecahkan suatu masalah melalui tahap-tahap metode ilmiah sehingga siswa dapat mempelajari pengetahuan yang berhubungan dengan masalah tersebut dan sekaligus memiliki keterampilan untuk memecahkan masalah (Trianah, 2019). Melalui tahap-tahap metode ilmiah dalam model PBL yang disajikan dalam LKS menuntun siswa untuk 
mendapatkan pengetahuannya secara mandiri. Selain itu, hasil penelitian dari Pariska menyimpulkan bahwa dengan menggunakan LKS berbasis masalah dapat meningkatkan hasil belajar siswa (Amin \& Sulistiyono, 2021).

Pada pembelajaran kimia dibutuhkan suatu pemahaman konsep yang matang agar siswa dapat memecahkan suatu permasalahan dalam bidang kimia di bangku pendidikan dan kehidupan nyata. (Widyasti. Wiratama \& Muderawan, 2020) .Pemahaman konsep memberikan pengertian bahwa materi-materi yang diajarkan kepada siswa bukan hanya sekedar rumus. Sehingga sudut pandang siswa tentang kimia menjadi lebih baik. Tujuan dari perubahan sudut pandang tersebut yaitu, agar siswa memiliki pemahaman konsep yang baik sehingga siswa lebih mudah mengerti akan konsep materi-materi dalam kimia (Sulistiyono et al., 2019). Harapannya agar siswa dapat memecahkan permasalahan kimia dengan baik. Menindaklanjuti masalah itu diperlukan adanya solusi untuk mengubah sudut pandang tersebut. Pergeseran sudut pandang ke arah yang lebih baik dapat terwujud dengan diterapkannya sebuah model pembelajaran yang mengaitkan materi kimia dengan fenomena kehidupan sehari-hari. Adapun model pembelajaran yang mampu mewujudkannya yaitu problem based learning.

Model pembelajaran problem based learning adalah suatu model pengajaran yang meng-gunakan masalah dunia nyata, sebagai suatu konteks bagi siswa untuk belajar tentang cara berpikir kritis, dan keterampilan pemecahan masalah, serta untuk memperoleh pengetahuan dan konsep yang esensial dari materi pelajaran. Dapat disimpulkan problem based learning merupakan model belajar, yang menggunakan masalah sebagai langkah awal dalam mengumpulkan dan mengintegrasikan pengetahuan baru (Nurhadi, 2004).

Model pembelajaran problem based learning juga memiliki karakteristik yang berbeda dengan model pembelajaran lainnya, adapun karakteristik pembelajaran berbasis problem based learning memposisikan siswa sebagai self directed problem solver melalui kegiatan kolaboratif, mendorong siswa untuk mampu menemukan masalah dan mengkolaborasinya dengan mengajukan dugaan-dugaan dan merencanakan penyelesaian, memfasilitasi siswa untuk mengeksplorasi berbagai alternatif penyelesaian dan implikasinya, serta mengumpulkan dan mendistribusikan informasi, melatih siswa untuk terampil menyajikan temuan, dan membiasakan siswa untuk merefleksi tentang efektivitas cara berpikir mereka dalam menyelesaikan masalah (Taufik, 2009).

Model problem based learning ini juga berfokus pada keaktifan siswa dalam kegiatan pembelajaran. model problem based learning merupakan model pembelajaran yang dapat membantu siswa untuk aktif dan mandiri dalam mengembangkan kemampuan berpikir memecahkan masalah melalui pencarian data, sehingga diperoleh solusi dengan rasional dan autentik (Muslimin Ibrahim, 2000). Ada beberapa langkah pembelajaran berbasis problem based learning yaitu orientasi siswa kepada masalah (tindakan guru menjelaskan tujuan pembelajaran, logistik yang dibutuhkan, memotivasi siswa aktif, pengajuan masalah, dan memotivasi siswa terlibat dalam aktivitas pemecahan masalah), mengorganisasi siswa untuk belajar (guru membantu siswa mendefinisikan dan mengorganisasi tugas belajar yang berhubungan dengan masalah tersebut), membimbing penyelidikan individual dan kelompok (guru mendorong siswa untuk mengumpulkan informasi yang sesuai dan melaksanakan eksperimen, untuk mendapatkan penjelasan pemecahan masalah), mengembangkan dan menyajikan hasil karya (guru membantu siswa dalam merencanakan dan menyiapkan karya yang sesuai seperti laporan, video, model dan membantu mereka untuk berbagai tugas dengan kelompoknya),menganalisis dan mengevaluasi proses pemecahan masalah (guru membantu siswa melakukan refleksi atau evaluasi terhadap penyelidikan mereka dalam proses-proses yang mereka gunakan) (Adiansha \& Sani, 2021).

Untuk mengatasi permasalahan di atas, perlu ada variasi model pembelajaran. Ada beberapa model pembelajaran, salah satunya adalah penggunaan LKS berbasis Problem Based Learning (PBL). LKS berbasis PBL ini berbentuk LKS yang menjabarkan masalah atau fenomena dalam kehidupan nyata atau kehidupan seharihari, kemudian peserta didik dituntut untuk menemukan konsep dari permasalahan yang telah dijabarkan. Format LKS berbasis PBL mengadaptasi dari sintaks pembelajaran berbasis PBL, yakni menjabarkan uraian permasalahan, petunjuk atau pengarahan penyelidikan, mengumpulkan informasi untuk pemecahan masalah, mempresentasikan atau menyajikan hasil pemecahan masalah, menganalisis dan mengevaluasi proses pemecahan masalah (Zainab, Rahmawanti \& Apriani, 2021) Melalui melalui penggunaan LKS yang dikembangkan ini menekankan pembelajaran siswa di kelas yang semula pasif menjadi aktif dan akan berpusat pada siswa. 
Pembelajaran kimia kurang lengkap jika tidak disertai dengan LKS dan praktikum, praktikum dalam proses pembelajaran kimia sudah diakui sebagai komponen penting dalam pembelajaran untuk siswa (Algiranto \& Sulistiyono, 2020). Proses pembelajaran kimia di sekolah harus dikemas dan dikelola dengan baik untuk terwujudnya pembelajaran yang bermakna [12]. Pembelajaran kimia dengan kerja praktek dalam proses pembelajaran kimia merupakan pembelajaran secara langsung berdasarkan pengalamannya sendiri (hands-on) (Trianah, 2021).

\section{METODE}

Penelitian ini merupakan penelitian pengembangan atau Research and Development (R\&D). Model penelitian dan pengembangannya menggunakan model 4D (define, design, develop, dan disseminate) (Trianto, 2015) .Dalam penelitian ini, produk yang dihasilkan adalah LKS kimia berbasis PBL. Tujuan LKS berbasis PBL untuk meningkatkan partisipasi dan hasil belajar siswa kelas X. Instrumen yang digunakan dalam penelitian ini berupa instrumen perangkat pembelajaran dan instrumen pengumpulan data. Instrumen perangkat pembelajaran berupa: RPP dan LKS, sedangkan instrumen pengumpulan data berupa: lembar validasi, lembar observasi keterlaksanaan RPP, angket partisipasi siswa, soal tes hasil belajar, dan angket respon siswa.

Teknik analisis data yang digunakan dalam penelitian ini adalah, Validitas instrumen dianalisis menggunakan Content Validity Ratio (CVR) dan Content Validity Index (CVI). Pemberian skor pada angket divalidasi dengan CVR, berikut teknik analisis data hasil validasi menggunakan persamaan sebagai berikut:

$$
C V R=\frac{\left(N_{e}-\frac{N}{2}\right)}{\frac{N}{2}}
$$

Keterangan:

$\mathrm{N}_{e}=$ Jumlah validator yang menyetujui

$N=$ Jumlah total validator

Analisis Reliabilitas Terhadap LKS kimia berbasis PBL ditentukan dengan menggunakan Interclass Correlation Coefficient (ICC) atau koefisien korelasi antar kelas. Nilai ICC dianalisis dengan menggunakan program SPSS 16.0. Fleiss (dalam Wahyu Widhiarso, 2005: 15) mengkategorikan tingkat reliabilitas seperti pada Tabel 1.

Tabel 1. Kategori Nilai ICC

\begin{tabular}{cc}
\hline Nilai ICC & Kategori \\
\hline$<0,40$ & Buruk \\
$0,41-0,60$ & Cukup \\
$0,61-0,75$ & Memuaskan \\
$>0,75$ & Istimewa \\
\hline
\end{tabular}

\section{Hasil dan Pembahasan}

Penelitian ini merupakan penelitian pengembangan atau Research and Development (R \& D) dengan produk LKS berbasis PBL untuk meningkatkan partisipasi dan hasil belajar peserta didik kelas X. Model penelitian dan pengembangannya menggunakan model 4D. Model 4D terdiri dari empat tahap pengembangan, yaitu pendefinisian (define), perancangan (design), pengembangan (develop), dan penyebaran (disseminate). Perangkat pembelajaran berupa RPP dan LKS berbasis PBL yang dikembangkan, serta instrumen pengambilan data berupa soal pretest-posttest harus divalidasi terlebih dahulu. Validasi dilakukan oleh ahli dan praktisi dengan memberikan angket penilaian validasi (Adiansha \& Sani, 2021). Hal tersebut dilakukan untuk mendapatkan penilaian perangkat pembelajaran dan instrumen pengambilan data agar layak digunakan dalam proses pembelajaran. Hasil analisis validitas instrumen perangkat pembelajaran dan instrumen pengambilan data disajikan pada Tabel 2, Tabel 3, dan Tabel 4.

Hasil validasi dan penilaian kelayakan di atas, secara keseluruhan dapat dinyatakan RPP dikategorikan sangat baik, sehingga layak digunakan dalam proses pembelajaran. Kemudian untuk penilaian oleh validator LKS berbasis PBL berdasarkan analisis validitas dan kelayakan, secara rinci LKS hasil pengembangan termasuk 
dalam kategori sangat baik dan bisa di gunakan untuk proses pembelajaran dan yang ketiga adalah hasil validitas soal pre-test dan post-test, dapat dinyatakan bahwa soal pre-test post-test dikategorikan sangat baik, sehingga layak digunakan untuk instrumen pengambilan data. Sesuai dengan hasil penelitian yang dilakukan oleh (Trianah, 2021) jika hasil produk pengembangan dapat digunakan jika telah memenuhi kriteria valid. Berdasarkan hasil analisis validitas di atas, semua instrumen baik perangkat pembelajaran maupun pengumpulan data berkategori sangat baik berdasarkan penilaian validator.

Tabel 2. Hasil Validitas RPP

\begin{tabular}{lcc}
\hline \multicolumn{1}{c}{ Aspek } & CVR & Kategori \\
\hline Identitas Mata Pelajaran & 0,99 & Sangat Baik \\
Perumusan Indikator & 0,99 & Sangat Baik \\
Pemilihan Materi Ajar & 0,99 & Sangat Baik \\
Pemilihan Sumber Belajar & 0,99 & Sangat Baik \\
Pemilihan Media Belajar & 0,99 & Sangat Baik \\
Model Pembelajaran & 0,99 & Sangat Baik \\
Skenario Pembelajaran & 0,99 & Sangat Baik \\
Penilaian & 0,99 & Sangat Baik \\
Jumlah CVR & 20,79 & Sangat Baik \\
CVI & $\mathbf{0 , 9 9}$ & \\
\hline
\end{tabular}

Tabel 3. Hasil Validitas LKS Berbasis PBL

\begin{tabular}{llc}
\hline \multicolumn{1}{c}{ Aspek } & CVR & Kategori \\
\hline Aspek Didaktik & 0,99 & Sangat Baik \\
Kualitas Materi dalam LKS & 0,99 & Sangat Baik \\
Kesesuaian LKS Berbasis PBL & 0,99 & Sangat Baik \\
Jumlah CVR & 2,79 & Sangat Baik \\
CVI & 0,99 & \\
\hline
\end{tabular}

Tabel 4. Hasil Validitas Soal Pretest-Posttest

\begin{tabular}{lcc}
\hline \multicolumn{1}{c}{ Aspek } & CVR & Kategori \\
\hline Indikator yang digunakan sesuai dengan KI dan KD. & 0,99 & Sangat Baik \\
Soal mempresentasikan seluruh indikator yang ada. & 0,99 & Sangat Baik \\
Menggunakan kata-kata baku. & 0,99 & Sangat Baik \\
Paket soal sesuai taksonomi Bloom & 0,99 & Sangat Baik \\
Ada metode penskoran dan perhitungan nilai & 0,99 & Sangat Baik \\
Ada kunci jawaban soal & 0,99 & Sangat Baik \\
Jumlah CVR & 5,94 & Sangat Baik \\
CVI & 0,99 & \\
\hline
\end{tabular}

Berdasarkan analisis reliabilitas LKS berbasis PBL dengan menggunakan ICC diperoleh hasil yang disajikan pada Tabel 5 .

Tabel 5. Reliabilitas Butir Soal LKS Uji Lapangan Terbatas

\begin{tabular}{lcc}
\hline \multirow{2}{*}{ Reliabilitas } & \multicolumn{2}{c}{ Kotelasi } \\
\cline { 2 - 3 } & Nilai & Kategori \\
\hline LKS I & 0,946 & Istimewa \\
LKS II & 0,877 & Istimewa \\
\hline
\end{tabular}

Hasil pada Tabel 5 dapat dilihat bahwa LKS I dan LKS II pada uji terbatas ini diperoleh kategori istimewa. Kategori tersebut dapat disimpulkan bahwa soal pada LKS berbasis PBL I dan LKS berbasis PBL II reliabel, sehingga peneliti tidak melakukan perbaikan terhadap inti materi pada butir soal dalam LKS. Sesuai dengan hasil penelitian yang telah dilakukan oleh (Algiranto \& Sulistiyono, 2020) bahswa pengembangan LKS bisa duterapkan jika hasil validasi oleh ahli termasuk dalam kategori minimal baik. 
Keterlaksanaan RPP Pada uji kelompik kecil dan uji coba kelompok besar, keterlaksanaan pembelajaran dinilai oleh observer. Ringkasan analisis keterlaksanaan RPP penilaian dari observer disajikan pada Tabel 6.

Tabel 6. Keterlaksanaan RPP

\begin{tabular}{|c|c|c|}
\hline Keterlaksanaan & Rata-rata IJA & Kategori \\
\hline \multicolumn{3}{|c|}{ Uji Coba Kelompok Kecil } \\
\hline Petremuan I & $100 \%$ & Layak \\
\hline Pertemuan II & $100 \%$ & Layak \\
\hline \multicolumn{3}{|c|}{ Uji Coba Kelompok Besar } \\
\hline Petremuan I & $100 \%$ & Layak \\
\hline Pertemuan II & $100 \%$ & Layak \\
\hline
\end{tabular}

Secara keseluruhan berdasarkan hasil keterlaksanaan RPP pada Tabel 11 di atas, baik pada uji lapangan terbatas maupun uji lapangan operasional diperoleh nilai IJA lebih dari 75\% yaitu sebesar 100\%. Hasil tersebut diperoleh kesimpulan bahwa RPP pertemuan I dan II dikategorikan layak digunakan.

Partisipasi Siswa dikatakan aktif berpartisipasi dalam proses pembelajaran apabila siswa aktif dan kondusif, menjalin hubungan timbal balik, dan menaati tata tertib. Gambar 1 ditunjukkan peningkatan partisipasi siswa sebelum dan sesudah pembelajaran menggunakan LKS berbasis PBL.

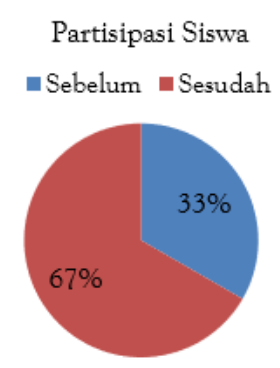

Gambar 1. Peningkatan Partisipasi Siswa

Gambar $1 \mathrm{di}$ atas, dapat dilihat bahwa rata-rata partisipasi sebelum pembelajaran menggunakan LKS berbasis PBL sebesar 33\% dan rata-rata partisipasi sesudah pembelajaran menggunakan LKS berbasis PBL sebesar 67\%. Apabila dianalisis menggunakan standard gain diperoleh nilai sebesar 0,6 dengan kategori tinggi.

Peningkatan partisipasi baik pada uji lapangan terbatas maupun uji lapangan operasional menggunakan angket sebelum dan sesudah pembelajaran menggunakan LKS berbasis PBL. Hasil yang diperoleh dari pengisian angket selanjutnya dianalisis dengan menggunakan standard gain untuk mengetahui seberapa peningkatannya. Sama halnya dengan peningkatan partisipasi, untuk mengetahui peningkatan hasil belajar kognitif peserta didik digunakan pula analisis dengan menggunakan standard gain. Uji lapangan terbatas dilakukan dengan jumlah peserta didik 18 orang sedangkan uji lapangan operasional dilakukan dengan jumlah peserta didik 38 orang. Siswa dikatakan aktif berpartisipasi dalam proses pembelajaran apabila siswa aktif dan kondusif, menjalin hubungan timbal balik, dan menaati tata tertib. Aspek partisipasi tersebut yang menjadi bahan pernyataan dalam angket partisipasi siswa. Hasil Belajar Siswa Peningkatan partisipasi siswa pada uji lapangan operasional ditunjukkan pada Gambar 2.

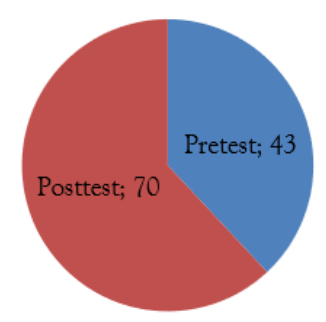

Gambar 2. Peningkatan Hasil Belajar Siswa 
Gambar 2 di atas, menunjukkan perbandingan nilai rata-rata pretest posttest dengan nilai pre-test sebesar 43 dan nilai post-test sebesar 70. Apabila dianalisis menggunakan standard gain diperoleh nilai sebesar 0,5 dengan kategori sedang. Hasil belajar kognitif melalui tes tertulis dalam bentuk pre-test dan post-test. Pretest dilakukan sebelum memulai pembelajaran dilakukan selama 45 menit dengan diberikan 20 butir soal pilihan ganda. Posttest dilakukan bagian akhir setelah selesai materi pembelajaran yang dilakukan selama 45 menit dengan 20 butir soal yang sama seperti pre-test.

Perbandingan nilai rata-rata pretest-posttest pada uji lapangan operasional dengan nilai pre-test sebesar 43 dan nilai post-test sebesar 70. Apabila dianalisis menggunakan standard gain diperoleh nilai sebesar 0,5 dengan kategori sedang. Hal ini berarti dengan perangkat pembelajaran LKS berbasis PBL dapat meningkatkan hasil belajar kognitif dengan kategori peningkatan sedang. Adanya peningkatan tersebut dikarenakan saat melakukan pre-test peserta didik belum mempunyai pengetahuan dan pengalaman. Setelah pembelajaran dilaksanakan, maka peserta didik mendapat pengetahuan melalui penyelidikan (Zainab, Novi Rahmawanti, 2021).

Proses pembelajaran kimia dengan menggunakan LKS berbasis PBL hasil pengembangan dilakukan dengan kegiatan pembelajaran berupa diskusi kelompok, eksperimen, dan demonstrasi. Hasil diskusi dipresentasikan oleh perwakilan kelompok yang dilanjutkan dengan tanya jawab. LKS berbasis PBL dapat menciptakan suasana belajar yang aktif dan kegiatan pembelajaran berpusat pada peserta didik. Selain itu, materi yang disajikan dengan pendekatann PBL memiliki kedekatan dengan kejadian di lingkungan sekitar peserta didik, sehingga materi yang disusun bermakna untuk dipelajari. Dengan demikian, LKS berbasis PBL dapat meningkatkan partisipasi dan kognitif peserta didik dalam proses pembelajaran. Dengan demikian pembelajaran kimia akan berjalan dengan baik apabila siswa diajak untuk melakukan pengamatan tentang fenomena alam secara sistematis dan menekankan pada pemberian pengalaman langsung dalam proses pembelajarannya (Hakim, \& Haris, 2020).

Kelayakan Peragkat Pembelajaran berdasarkan nilai yang diberikan oleh validator pada lembar validasi RPP, LKPD, dan hasil respon siswa terhadap LKS berbasis PBL. Secara ringkas hasil kelayakan RPP disajikan pada Tabel 5, kelayakan LKS pada Tabel 6, dan hasil respon siswa pada Tabel 7.

Tabel 5. Hasil Kelayakan RPP

\begin{tabular}{lcc}
\hline \multicolumn{1}{c}{ Aspek } & Nilai & Kategori \\
\hline Identitas Mata Pelajaran & 5 & Sangat Baik \\
Perumusan Indikator & 4,7 & Sangat Baik \\
Pemilihan Materi Ajar & 0,5 & Sangat Baik \\
Pemilihan Sumber Belajar & 0,5 & Sangat Baik \\
Pemilihan Media Belajar & 0,5 & Sangat Baik \\
Model Pembelajaran & 0,5 & Sangat Baik \\
Skenario Pembelajaran & 0,5 & Sangat Baik \\
Penilaian $\quad 0,5$ & Sangat Baik \\
\hline \multicolumn{1}{c}{ Jumlah } & 36,67 & Sangat Baik \\
\hline
\end{tabular}

Kelayakan RPP ditinjau dari keterlaksanaan RPP dari lembar observasi keterlaksanaan RPP pada proses pembelajaran. Setiap pertemuan observer 2 orang untuk mengamati proses pembelajaran kemudian mengisi lembar observasi keterlaksanaan RPP. RPP yang layak digunakan dalam kegiatan pembelajaran apabila keterlaksanaannya lebih dari $75 \%$.

Tabel 6. Hasil Kelayakan LKS Berbasis PBL

\begin{tabular}{ccc}
\hline \multicolumn{1}{c}{ Aspek } & Nilai & Kategori \\
\hline Aspek Didaktik & 4,5 & Sangat Baik \\
Kualitas Materi dalam LKS & 4,4 & Sangat Baik \\
Kesesuaian LKS Berbasis PBL & 4,5 & Sangat Baik \\
\hline \multicolumn{1}{c}{ Jumlah } & 13,5 & Sangat Baik \\
Rata-rata & 4,45 & \\
\hline
\end{tabular}


Tabel 7. Analisis Respon Siswa

\begin{tabular}{lcc}
\hline \multicolumn{1}{c}{ Aspek } & Nilai & Kategori \\
\hline Tampilan LKS & 4,24 & Baik \\
Ketrampilan memecahkan masalah dalam LKS & 4,22 & Baik \\
\hline Rata-rata & 4,23 & Baik \\
\hline
\end{tabular}

Hasil analisis respon siswa diperoleh nilai 4,23 dengan kategori baik. Respon siswa terhadap LKS kimia berbasis PBL menunjukkan respon yang baik sehingga mampu memotivasi siswa untuk berpartisipasi dalam mengetahui konsep dan meningkatkan hasil belajar.

\section{SIMPULAN}

Berdasarkan hasil analisis data dan pembahasan yang telah dilakukan, diperoleh kesimpulan sebagai berikut: Telah dihasilkan LKS kimia berbasis PBL yang layak untuk meningkatkan partisipasi dan hasil belajar siswa SMA kelas X. LKS berbasis PBL dapat meningkatkan partisipasi dan hasil belajar siswa SMA kelas X. Respon siswa setelah menggunakan LKS kimia berbasis PBL adalah baik.

\section{Daftar Pustaka}

Adiansha, A. A., \& Sani, K. (2021). Pengaruh Model Brain Based Learning dan Problem Based Learning terhadap Keterampilan Berpikir Kompleks Matematis ditinjau dari Kreativitas Siswa Sekolah Dasar di Kabupaten Bima. Jurnal Pendidikan MIPA, 11(1), 36-44. DOI: https://doi.org/I0.37630/jpm.vIIiI.454

Algiranto \& Sulistiyono. (2020). Development of Physics Students Worksheets with Scientific Approaches to Improve Skills Critical Thinking and High School Student Learning Outcomes Pengembangan Lembar Kerja Peserta Didik Fisika dengan Pendekatan Saintifik untuk Meningkatkan Keterampilan. Jurnal Geliga Sains: Jurnal Pendidikan Fisika, 8(2), 107-113. DOI: http://dx.doi.org/I0.3I258/jgs.8.2.107-II3

Amin, A., \& Sulistiyono, S. (2021). Pengembangan Handout Fisika Berbasis Contextual Teaching and Learning (CTL) Untuk Meningkatkan Aktivitas Dan Hasil Belajar Fisika Siswa SMA. Jurnal Pendidikan Fisika Undiksha, 11(1), 29. https://doi.org/10.23887/jjpf.v11i1.33436

Lisnawati. (2021). Pengembangan Lks Berbasis Lingkungan Materi Perubahan Fisika Dan Kimia IPA Terpadu Di Kelas VII SMPN 2 Pulau Malan Tahun Ajaran 2020/2021. SCIENCE : Jurnal Inovasi Pendidikan Matematika Dan IPA, 1(1), 46-54. DOI: https://doi.org/10.51878/science.v1i1.217

Muslimin Ibrahim. (2000). Pengajaran Berdasarkan Masalah. UNESA Press.

Nurhadi. (2004). Pembelajaran Kontekstual dan Penerapannya dalam KBK. UM Press.

Sulistiyono, Mundilarto, \& Kuswanto, H. (2019). Pengembangan Instrumen Penilaian Kerja Laboratorium Fisika untuk Mengukur Sikap dan Tanggung Jawab Siswa. Jurnal Materi Dan Pembelajaran Fisika (JMPF), 9(1), 43-49.

Sulistiyono, S. (2017). Pengembangan Lembar Kerja Siswa dengan Pendekatan Kerja Laboratorium untuk Meningkatkan Keterampilan Proses Fisika. Science and Physics Education Journal (SPEJ), 1(1), 59-64. https://doi.org/10.31539/spej.v1i1.69

Taufik, A. (2009). Inovasi Pendidikan Melalui Problem Based Learning. Kencana Prenada Media Group.

Trianah, Y. (2019). Penerapan Pendekatan Sains Teknologi Masyarakat (STM) Pada Materi Asam Basa Terhadap Aspek Kesadaran Lingkungan, Respon, Dan Hasil Belajar Kimia Siswa SMK N 3 Lubuklinggau. Jurnal Perspektif Pendidikan, 13(2), 150-158. DOI: https://doi.org/I0.31540/jpp.vI3i2.950 
Trianah, Y. (2020). Keefektifan Pembelajaran Kimia Berbasis Etnosains Terhadap Keterampilan Proses Sains Siswa SMK Negeri Tugumulyo. Jurnal Perspektif Pendidikan, 14(1), 58-66. DOI: https://doi.org/I0.31540/ipp.vI4iI.998

Trianah, Y. (2021). Pengembangan LKPD Kimia Berbasis Inkuiri Materi Kimia Tanah Untuk Meningkatkan Penguasaan Konsep Siswa SMKN Pretanian 2 Tugumulyo. Jurnal Perspektif Pendidikan, 15(1), 81-90. DOI: https://doi.org/I0.3I540/ipp.vI5iI.I342

Trianto. (2015). Model Pembelajaran Terpadu. Bumi Aksara.

Widyasti. Wiratama \& Muderawan. (2020). Uji Validasi Pengembangan Lembar Kerja Siswa Berbasis Pendekatan Saintifik. Jurnal Ilmiah Pendidikan Dan Pembelajaran, 4(April 2020), 79-85. http://dx.doi.org/I0.23887/jipp.v4iI.I559I

Zainab, Novi Rahmawanti, H. A. (2021). Pengembangan Lembar Kerja Siswa Berbasis Inkuiri Terbimbing Pada Materi Hidrolisis Garam Di MAN 1 Banjarmasin. Dalton: Jurnal Pendidikan Kimia Dan Ilmu Kimia, 4(2), 64-75. DOI: http://dx.doi.org/I0.3I602/dl.v4i2.5942 